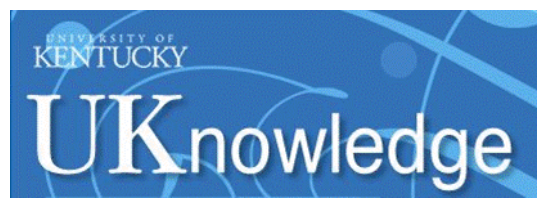

University of Kentucky

UKnowledge

Microbiology, Immunology, and Molecular Genetics Faculty Publications

Microbiology, Immunology, and Molecular Genetics

$9-2015$

\title{
Muscle Weakness during Aging: A Deficiency State Involving Declining Angiogenesis
}

\author{
Charles T. Ambrose \\ University of Kentucky, cambros@uky.edu
}

Follow this and additional works at: https://uknowledge.uky.edu/microbio_facpub

Part of the Geriatrics Commons, Molecular Genetics Commons, and the Neurology Commons

Right click to open a feedback form in a new tab to let us know how this document benefits you.

\section{Repository Citation}

Ambrose, Charles T., "Muscle Weakness during Aging: A Deficiency State Involving Declining Angiogenesis" (2015). Microbiology, Immunology, and Molecular Genetics Faculty Publications. 113.

https://uknowledge.uky.edu/microbio_facpub/113

This Article is brought to you for free and open access by the Microbiology, Immunology, and Molecular Genetics at UKnowledge. It has been accepted for inclusion in Microbiology, Immunology, and Molecular Genetics Faculty Publications by an authorized administrator of UKnowledge. For more information, please contact UKnowledge@lsv.uky.edu. 


\section{Muscle Weakness during Aging: A Deficiency State Involving Declining Angiogenesis}

Digital Object Identifier (DOI)

https://doi.org/10.1016/j.arr.2015.03.005

Notes/Citation Information

Published in Ageing Research Reviews, v. 23, part B, p. 139-153.

Copyright @ 2015 Elsevier B.V.

(c) 2015. This manuscript version is made available under the CC-BY-NC-ND 4.0 license

http://creativecommons.org/licenses/by-nc-nd/4.0/.

The document available for download is the author's post-peer-review final draft of the article. 


\begin{abstract}
... $160 \ldots$
This essay begins by proposing that muscle weakness of old age from sarcopenia is due in large part to reduced capillary density in the muscles, as documented in 9 reports of aged persons and animals. Capillary density (CD) is determined by local levels of various angiogenic $\underline{\text { factors, }}$ which also decline in muscles with aging, as reported in 7 studies of old persons and animals. There are also numerous reports of reduced CD in the aged brain and other studies showing reduced $\mathrm{CD}$ in the kidney and heart of aged animals. Thus a waning angiogenesis throughout the body may be a natural occurrence in later years and may account significantly for the lesser ailments (physical and cognitive) of elderly people. Old age is regarded here as a deficiency state which may be corrected by therapeutic angiogenesis, much as a hormonal deficiency can be relieved by the appropriate hormone therapy. Such therapy could employ recombinant angiogenic factors which are now commercially available.
\end{abstract}

Key Words: muscle weakness, sarcopenia, capillary density, angiogenesis, therapeutic angiogenesis, deficiency state 


\section{Muscle Weakness during Aging : a Deficiency State Involving Declining Angiogenesis}

\section{Contents}

1. Introduction

Part I: Decreased Angiogenesis in Muscles with Age

2. Muscle weakness and waning angiogenesis

2.1. Reduced capillary density and angiogenic factors in skeletal muscles

2.2. Suppressing angiogenesis with an antibody or an enzyme

2.3. Enhancing angiogenesis with recombinant VEGF

3. Muscle weakness and waning muscle stem cells

4. Muscle weakness and waning hormone levels

4.1. Androgens

4.2. Estrogens

4.3. Thyroid hormones

5. Muscle weakness and physiologic angiogenesis

6. Summary for Part I

\section{Part II: Therapy of Muscle Weakness}

7. Treatment of muscle weakness by therapeutic angiogenesis

7.1. Cardiac studies in animals \& people

7.2. Skeletal muscle studies in animals 
7.3. Skeletal muscles studies in people

8. Angiogenic factors

8.1. Single agents

8.1.1. VEGF

8.1.2. FGF

8.2. Agents in synergism

8.2.1. Angiopoietin

8.2.2. Platelet derived growth factor.

8.3. Further considerations

9. Various routes of angiogenic therapy

9.1. Nose

9.2. Lungs

9.3. Buccal cheek

9.4. Tongue

10. Other issues in therapeutic angiogenesis

10.1. Absorption of AG factors

10.2. Sustained treatment

10.3. Side effects

11. Summary for Part II

12. Conclusions

Footnotes

Acknowledgements \& References

Tables 


\section{TEXT _.. $7229 \ldots 50615$}

\section{Introduction}

In the years before succumbing to a fatal illness (cardiovascular disease, malignancy, pneumonia, etc.), most older persons complain of several lesser ailments - occasional memory lapses/pauses (senior moments) and muscle weakness. I suggest that these symptoms of aging may share a common pathology - i.e., a deficient microcirculation secondary to the age-linked decline of angiogenic (AG) factors. Loss of muscle strength is the main focus of this essay, while minor memory problems of old age are secondary here and akin to the more serious cognitive decline (senile dementias) discussed in previous papers. Ambrose 2012, 2013, 2015A

The physical and mental deterioration characterizing old age has been ascribed to the numerous causes. Comfort 12974, Hayflickl 1975, Kowald 1996, Weinert 2003, Duc 2014 In 1974, a reviewer commented that there seems to be one theory on aging for every published investigator. Marx 1974 The various proposals have been considered under two broad groupings: developmental (genetic) versus stochastic (random) ... with specific theories falling under one group or sometimes under both. It is now generally assumed that most cases of aging are due to several deleterious influences. Correcting one of them might slow or moderate the general deterioration.

The various theories of aging (e.g., longevity gene, somatic mutations, epigenetic modifications, stress, thymic atrophy, free radical toxicity, etc.) seem tenable but suggest no concrete means of therapy ... or at least any measures readily available for general use now. However, practical therapeutic approaches are offered by theories which invoke a deficiency state - e.g., hormonal levels falling with age. Another deficiency state is the age-linked decline of angiogenic growth factors -- the major concern of this paper. 
By way of background for this essay, the microcirculation throughout the body is commonly designated as capillary density (CD) and is determined in large part by local levels of angiogenic (AG) factors - e.g., vascular endothelial growth factor (VEGF), fibroblastic growth factor (FGF), and others. The brain will be discussed briefly first, because data showing reduced $\mathrm{CD}$ there support the analogous reduction to be discussed later in muscles. As documented in an earlier paper, reduced cerebral capillary density has been reported in the brains of aged people (5 reports), those with Alzheimer's disease (5 reports), and also old rats and mice (13 reports). Ambrose 2015A: Tables $2 \& 3$ See Footnote 1. These data led to the Neuroangiogenesis Hypothesis (NAG hypothesis) advanced in that paper as one cause of impaired cognition in persons with senile dementias.

The levels of angiogenic factors have not been reported in the brains of aged persons, but one recent study found diminished levels of VEGF in the parietal cortex of old rats. Viboolvorakul 2014 When specifically looked for, a comparable decline of AG factors in the aged human brain may likely be found, consistent with the above report on rats and comparable to lower levels in aged muscle -- as treated next. My review of levels of CD and AG factors in the aging brain led to examining the literature for similar studies in the muscles of aged people and animals, where depressed levels have indeed been found. This later review is the basis for presenting here a view of age-linked muscle weakness which can be termed the MAAG hypothesis (for muscle-associated angiogenesis) -- a corollary to the NAG hypothesis.

Muscle strength appears influenced directly not only by AG factors (via CD) but also by muscle stem cells and both secondarily by certain hormones. The waning muscle mass in older persons reflects the age-related decrease in progenitor stem cells, which are acted upon by hormones (Section 3). Considerable data indicate that the age-associated falling levels of various 
hormones directly influence declining levels of AG factors in older persons (Section 4). Matrix proteins (fibronectin, laminin, etc.) interacting with various growth factors may also affect muscle stability/strength via angiogenesis. Arthur 1998, Sadoun 2003

This essay has two parts: Part I concerns angiogenic factors, stem cells, and hormones in the context of muscle weakness, while Part II suggests therapeutic options for relieving muscle weakness with angiogenic agents. These are now commercially available in recombinant forms, and their use would seem comparable to that of various hormones in their respective deficiency states.

\section{Part I: Decreased Angiogenesis in Muscles with Age}

\section{Muscle weakness and waning angiogenesis}

In aged persons, muscle weakness and diminished exercise tolerance are commonly ascribed to a failing heart and/or diseased lungs - i.e., to a reduced level of oxygenated blood available to the body tissues. Wagner 2006 Atherosclerosis, strokes, injuries, and a sedentary life style also lead to muscle weakness due to a reduced skeletal muscle mass, termed sarcopenia. In the elderly this condition is more conspicuous in the legs than in the arms and trunk, perhaps because the latter are being moved even when sitting. Borkan 1983: Table 2 Sarcopenia is defined as “appendicular skeletal muscle mass ... being less than two standard deviations below the mean

of a young reference group." Baumgartner 1998 By age 80, in both sexes there is "a 30-50\% decrease in skeletal muscle mass" due to loss in number of muscle fibers. Faulkner 2007 Sarcopenia is associated with reduced local CD and reduced levels of AG factors, as documented below.

2.1. Reduced CD and AG factors in skeletal muscles 
Five reports of reduced $\mathbf{C D}$ in lower limb muscles of elderly persons are presented in Table 1. Four such studies in the skeletal muscles of aged laboratory animals are listed in Table 2. Lower levels of AG factors have been found in skeletal muscles of the aged - 4 reports in aged people (Table 3) and 4 in old animals (Table 4). In animal muscle studies, experimental support for role of VEGF in maintaining CD comes from two opposite approaches: suppressing endogenous levels of VEGF or correcting low levels (enhancing angiogenesis) with exogenous VEGF.

2.2. Suppressing angiogenesis with an antibody or an enzyme

Amaral et al. tested rats in which exercise training induced on three consecutive days was shown to increase $\mathrm{CD}$ in skeletal muscles. Monoclonal VEGF neutralizing antibody was injected intraperitoneally on Day $-1,+1, \&+2$ of the 3 -day exercise protocol. The CD (capillary intersections $/ \mathrm{mm}^{2}$ ) in the tibialis anterior muscle on Day 3 was 129 in the control rats and reduced to 108 in the antibody-treated rats. A comparable decline was found in the gastrocnemius muscle. Amaral 2001: Fig. 5

Several groups of investigators have depleted VEGF throughout the gastrocnemius muscle of transgenic mice by the local injection of a recombinant cre recombinase adenoassociated viral vector. Tang 2004, Wagner 2006 Tang et al. found that this procedure reduced the expression of three isoforms of VEGF in the injected muscles. Correspondingly, the local capillary density was reduced to $64 \%$ by week 4 and was $69 \%$ on week 8 .

2.3. Enhancing angiogenesis with recombinant VEGF 
The opposite approach has involved administering growth factors to animals and measuring CD in leg muscles. Rivard et al. created hind limb ischemia in both old and young rabbits, which were injected with recombinant VEGF on postoperative day 10 via the iliac artery of the affected limb. On Day -10 (before injection) and Day 40 the average CDs (expressed as capillaries $/ \mathrm{mm}^{2}$ ) in young rabbits were $170 \& 280(\uparrow 64 \%)$ and in old rabbits were $130 \& 190$ (个46\%). Rivard 1999 Comparable results were obtained in similar experiments with mice.

While diminished local levels of AG factors and the resulting reduced CD may account directly for muscle weakness and sarcopenia, other biological processes may also be involved e.g., a reduced presence of myogenic stem cells and diminished levels of various hormones.

\section{Muscle weakness and waning muscle stem cells}

In higher animals after birth, the maintenance and regeneration of skeletal muscles involve tissue-specific stem cells - a.k.a., myogenic precursor cells, progenitor cells, or satellite cells. Sieveking 2009 These reside adjacent to mature myocytes beneath the lambia propria and are quiescent until activated by muscle injury or exercise. Either stimulus induces proliferation of the precursor cells and formation of nascent myotubules. Conboy 2002 This activation is under control of the Notch and related signaling pathways. (Footnote 2)

During old age, the regenerative capacity of muscle declines because the stem cells become less activated via the Notch pathway. Conboy 2003, Brack 2007, Carlson 2008 Discussion of it is beyond the scope of this essay except for the following conclusion. The various pathways responsible for muscle repair are regulated by "systemic factors" which change with age. Wagers 2005, ;1; Conboy 2005 These factors were not specified but likely include hormones. For example, Sinha-Hikim et al. found that testosterone administered to elderly men increased the number of 
muscle satellite cells. Sinha-Hikim 2006 Tateishi-Yuyama et al. "reported that the CD34-fraction of bone marrow stem cells" synthesize VEGF, bFGF, and Ang-1. Tateishi-Yuyama 2002 Thus muscle stem cells may provide paracrine AG factors in muscle areas.

Stem cells have been used therapeutically. Tateishi-Yuyama et al. implanted bone marrow-mononuclear cells (including endothelial progenitor cells) into ischemic limbs of persons with peripheral arterial disease and noted new collateral vessel formation, as disclosed in angiograms. The subjects reported increased pain-free walking times and reduced leg rest pain. Ischemic ulcers and gangrene were also lessened. Tateishi-Yuyama 2002

\section{Muscle weakness and waning hormone levels}

In a 1997 article entitled "The Endocrinology of Aging," Lamberts et al. ascribed loss of muscle strength in aged persons to diminished levels of various agents -- insulin, thyroxine, and several other hormones: dehydroepiandrosterone, testosterone, estrogen, or growth

hormone/insulin-like GH. Lamberts 1997 Of these, testosterone, estrogen, and thyroxine will be discussed below because of the abundant data showing that their actions on muscles and other tissues involve angiogenesis.

\subsection{Androgens}

An association between androgens and angiogenesis has been found in the prostate, heart, skeletal muscles, and brain of mice, rats, men, and even some song birds.

Castration of male mice resulted in a decreased VEGF content of ventral prostate tissue. Joseph 1997 The prostates of adult rats injected with dehydrotestosterone (DHT) showed a "a fourfold increase in VEGF specific activity." Sordello 1998 Numerous papers have reported that 
androgens up-regulate VEGF in cultures of normal and malignant human prostatic cells. ${ }^{\text {Joseph }}$ 1997, Sordello 1998, Eisermann 2013

In a rat model of myocardial infarction (ligation of a coronary artery), castration of males impaired the expression of VEGF in the ischemic myocardium. ${ }^{\text {Chen 2012a }}$ Here testosterone replacement therapy promoted angiogenesis in the myocardium, as measured 28 days after infarction. In a mouse hind limb ischemia model, castrated male mice showed a reduced CD in the affected limb but a restored vacularization upon treatment with an androgen. Sieveking 2010 The authors concluded that androgens exerted a proangiogenic effect which depends on VEGF and involves the mobilization of angiogenic-progenitor cells to sites of ischemia. Sieveking 2009, 2010

In older men, exogenous testosterone increases skeletal muscle mass, thus reversing Sarcopenia. Uban 1995, Bhasin 1996, Sih 1997, Snyder 1999, Ferrando 2002, Wittert 2003, Sinha-Hikim 2006, Atkinson 2010,

The seasonal acquisition of song capacity in some canaries and finches is related to rising levels of testosterone, which trigger neuronal production in the higher vocal center (HVC). Chen 2013 This is preceded by a burst of local endothelial cell division and angiogenesis, as evidenced by a rise in VEGF mRNA and VEGF protein. Cultures of canary HVC endothelial cell increased their rate of division in response to VEGF but not to testosterone. This suggests that in the brains of these birds testosterone induces the paracrine production of VEGF.

\subsection{Estrogens}

Morales et al. examined several human umbilical endothelial cell culture systems and found that $17 \beta$-estradiol promoted migration and proliferation of the cells and formation of capillary-like networks. Morales 1995 The authors wrote that estradiol "enhances the multiple components of angiogenesis activity in vitro" and may augment the action of angiogenic growth 
factors in tissues with either high estrogenic content or abundant estrogen responsiveness. This association may account for women having a higher incidence of various vasculitic diseases. The effect of $17 \beta$-estradiol modulating angiogenesis was also studied by others. Rubanyi 2002

\subsection{Thyroid hormones}

These hormones induce neovascularization in various settings - muscles, the heart, brain, and tumors. Luidens 2010, Zhang 2010 As outlined by Liu et al., the process begins for thyroid hormones at cell surface receptors on endothelial and muscle cells (e.g., integrin $\alpha v \beta 3$ ). The hormone signal is transduced via this receptor for the transcription of angiogenic-relevant genes, which leads to the synthesis and secretion of AG proteins. ${ }^{\text {Liu }} 2014$ Mousa et al. wrote that the hormone and its analogues modulate the "activities of multiple vascular growth factors receptors and their ligands" - thus linking this hormone to angiogenesis. Mousa 2014 Four experimental examples of thyroid-related angiogenesis follow.

Heart failure (“cardiac microvascular impairment") was produced in mice within a year of being fed propylthiouracil (PTU) to make them hypothyroid. Chen 2012 Triiodothyronine (T3) administered for three day induced significant capillary growth in the heart.

The forebrain regions of thyroidectomized rats showed decreased $\mathrm{CD}$. Thyroxine $\left(\mathrm{T}_{4}\right)$ or a thyroid analog "normalized" the blood vessel density. Schlenker 2008 Decreased brain angiogenesis (a "reduced complexity and density of microvessels") was found in young rats treated with PTU for 21 days to induce hypothyroidism. Zhang 2010

The severe mental retardation in cretinism has generally been ascribed to the direct effect of hypothyroidism on CNS neurons and myelination. ${ }^{\text {Zhang }} 2010$ But, as the above examples in rats 
suggest, the retardation might result primarily from a deficient cerebral angiogenesis and secondarily from defective/deficient neurons.

In summary, the above studies raise the possibility that the deficiency of one or more relevant hormones may lead to sarcopenia or otherwise impair function because of reduced angiogenesis.

\section{Enhanced Muscle strength and physiologic angiogenesis}

Exercise induces increased $\mathrm{CD}$ and the release of AG factors in the muscles of people

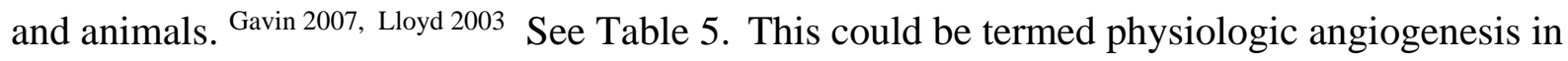
contrast to pharmacologic/therapeutic angiogenesis, discussed later in Part II. Such AG factors may exert a beneficial paracrine effect on endothelial cells and perhaps on myogenic progenitor cells and thus help reverse sarcopenia. Upon entering the circulation, the factors could stimulate angiogenesis in distant sites - i.e., have an endocrine effect. Gerontologists have long advocated walking to help maintain/improve mobility (muscle strength) and to benefit the cardiovascular system -- possibly adding a year or so of life. ${ }^{\text {Pafenbarger } 1986}$

Educators have also encouraged walking, since this has been thought to enhance learning

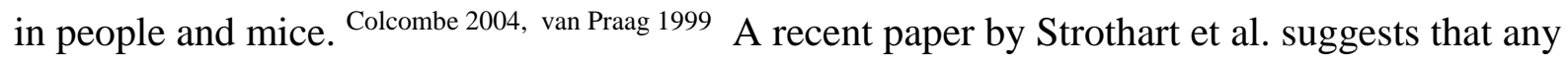
benefit in cognition from exercise may be a placebo effect, while an article by Hillman et al. confirms "the importance of physical activity on mental development." Strohart 2014, Hillman 2014 Exercise has an immediate effect of increasing circulation in the brain from vasodilatation, but it may provide a long term effect by increasing cerebral capillary density. Isaacs et al. observed increased angiogenesis in the rat cerebellum after it underwent vigorous physical activity. Isaacs 1992 Ding et al. reported that aged rats run daily for three weeks in a treadmill showed increased 
cerebral CD and elevation of VEGF mRNA ( $\uparrow 27 \%)$ and VEGF protein ( $\uparrow$ c.20\%) in the motor cortex and striatum. Ding 2006: Fig. $4 \& 6$

Table 5A shows increased local CD and/or elevated levels of VEGF from 21 reports on exercised muscles in people and animals. Human subjects (15 studies) exercised on a bicycle ergometer or single leg extension device, while small animals (6) were run on a circular treadmill. Table 5B shows 10 studies involving electrical stimulation with electrodes implanted into the flexor muscle of one leg of a rat or rabbit. In both types of experiments, biopsies were taken from the flexor muscles of animals or the vastus lateralis or other lower muscle of human subjects. Experimental and control biopsies were examined for evidence of increased vascularity ( $\uparrow C D$ ) and/or for levels of VEGF protein and VEGF mRNA. Representative of these studies on human subjects are the four following reports - the first two showing increased CD in muscles with exercise and the last two illustrating elevated muscle levels of VEGF with exercise.

Denis et al. examined two groups of men (G20: age $22 \pm 3$ yrs and G60: age $62 \pm 4$ yrs) who trained for 20 weeks pedaling a bicycle ergometer at $75 \mathrm{rpm}$ for $60 \mathrm{~min} /$ day, 4 times a week. Needle biopsies were obtained from the vastus lateralis muscle before and after training. Capillary density $\left(\mathrm{cap} / \mathrm{mm}^{2}\right.$ ) in the G20 group increased from $316 \pm 42$ to $396 \pm 73$ (个25\%). The CD in the G60 group rose from $308 \pm 48$ to $409 \pm 55$ ( $\uparrow 32 \%)$. Denis 1986

Gavin et al. observed increased capillarization ("capillary contacts" = cc) and levels of VEGF mRNA in the vastus lateralis in both young men (19-30 yrs) and old men (56-74 yrs) after 8 weeks of aerobic exercise. Capillary density $\left(\mathrm{cc} / \mathrm{mm}^{2}\right)$ in young men rose from $264 \pm 16$ to $341 \pm 29(\uparrow 29 \%)$ and in old men from $303 \pm 28$ to $350 \pm 63(\uparrow 15 \%)$. Gavin 2007 
Richardson et al. subjected young males to the exercise stimulus of a single leg kneeextensor ergometer. Biopsies of vastus lateralis muscle revealed VEGF mRNA levels of 0.38 \pm 0.04 before exercise and $7.1 \pm 1.8$ one hour afterwards. Richardson 1999

Gustafsson et al. followed healthy males who underwent 8 weeks of a one-legged kneeextension program. One day after the $7^{\text {th }}$ training session, muscle biopsies showed a two-fold increase in both VEGF mRNA and VEGF protein expression. Gustafsson 2001, 2002

Relevant to this essay's concern with aging is that the increased CD and elevated levels of AG factors were often less in the challenged muscles of old animals and elderly people than in those of their younger counterparts. For example, Adolfsson et al. found that exercise increased CD in young rat muscles from a baseline value of $460 \rightarrow 710(\uparrow 54 \%)$ and in old rats from $395 \rightarrow 484(\uparrow 23 \%)$. Adolfsson 1981 The same trend was found in several others reports, including that of Gavin et al above, where the young human subjects showed a $29 \%$ increase and the elderly only a $15 \%$ increase. Coggan 1992, Ryan 2006, Gavin 2007.

\section{Summary of Part I and an Overview of Angiogenesis in Muscles during Aging}

The above review from the literature on muscle physiology is the basis of the muscleassociated angiogenesis hypothesis. Tables $1 \& 2$ of this essay present data from 9 reports showing that $\boldsymbol{C D}$ declines in the skeletal muscles of both people and animals with age. These reports are complemented by similar data from other areas of the body. In a previous publication are summarized 18 studies showing reduced $\mathrm{CD}$ in the aged brains of people and animals. ${ }^{\text {Ambrose }}$

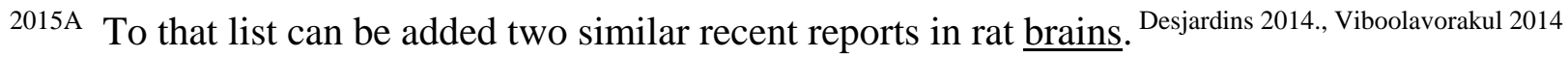

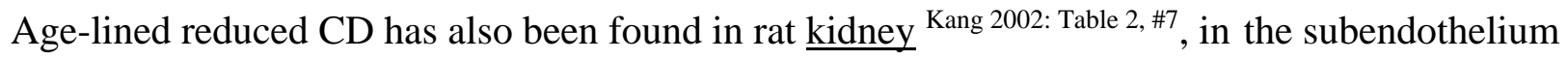

of rat heart ${ }^{\text {Iemitsu } 2006}$, and in sponges placed in wounds of mice. ${ }^{\text {Sadoun } 2003}$ Thus there are $\mathbf{3 2}$ 
reports of reduced levels of CD in various organ systems (and sponge inserts) of aged subjects and animals.

Tables 3 \& 4 present data from 7 reports showing reduced levels of AG factors in the muscles of aged people and animals. Reduced levels of AG factors have also been found in the brain (left parietal cortex) of aged rats Viboolvorakul 2014 , in the heart (left ventricular wall) of aged rats Iemitsu 2006, and in two reports of sponge implants in mice. Reed 1998, Sandoun 2003 Thus there are 11 reports of depressed levels of AG factors in various organs (or implants) of aged persons and animals. These two sets of data $(\mathbf{3 2}+\mathbf{1 1})$ strongly suggest that reduced CD and lowered levels of AG factors occur throughout the body in aged persons and in those old animals studied.

But the decline of $\mathrm{CD}$ and $\mathrm{AG}$ levels may not be uniformly expressed throughout the body. To date, there is no documented concordance between muscle weakness and cognitive decline in people, indicating either a differential decline in each organ system or that other influences may affect aging in them. But correcting one influence (e.g., a reduced CD) theoretically might benefit an aging brain or tired old muscles or both. Finally, mankind isn't helped by another theory on aging unless it offers tangible therapeutic options, which the angiogenesis hypotheses on aging do. These options are discussed below at length in Part II.

\section{Part II: Therapy of Muscle Weakness}

\section{Treatment of muscle weakness by therapeutic angiogenesis}

Seeking to delay the decline in health associated with aging, millions of Americans consume various vitamins and sundry supplements -- e.g., chondroitin sulfate \& glucosamine, hormones (testosterone, thyroxin), fish oil, ginkgo biloba, etc. Others have received periodic injections of anti-aging agents -- e.g., $\mathrm{B}_{12}$, gonadal extracts, procaine $\mathrm{HCl}$, etc. Theoretically, the 
process of aging should be slowed by certain biological agents. In 1974, Alex Comfort listed the following: radioprotectants, protein synthesis inhibitors, anti-crosslinking agents, lysosome stabilizers, antioxidants, immunosuppressants, and hormones. Comfort 1974 To these hypothetical agents now might be added amyloid destabilizers, anti-telomerases and, according to this essay, readily available ones -- e.g., recombinant angiogenic cytokines.

Attempts at therapeutic angiogenesis began over twenty years ago in animals with an experimentally induced ischemic myocardium (e.g., by ameroid constriction of the left circumflex artery) or ischemic skeletal muscles (e.g., ligation of femoral artery in hind limb). Banai 1991, Baffour 1992 First phase trials in patients with myocardial insufficiency soon followed. Henry 1998, Schumacher 1998 Studies in both animals and people, as noted below, have yielded practical information about angiogenic factors (e.g., safe levels) applicable to the potential treatment of muscle weakness of the aged -- hence the following brief review of cardiac and muscle studies.

\subsection{Cardiac studies in animals \& people}

Lin et al. described cardiac sarcopenia in mice. ${ }^{\text {Lin }} 2008$ Myocyte numbers decrease while there is increased fibrosis, accounting for the heart generally becoming thicker with age. Lin et al. suggest that "cardiac sarcopenia may explain, in part, why elderly patients respond poorly to cardiovascular events."

In recent therapeutic studies on the heart, either of two classes of agents was introduced into the ischemic myocardium of animals and later of people - the recombinant protein of various growth factors or their genes (naked DNA as a plasmid or via a viral vector). Several investigators have discussed these two approaches and have concluded that "protein therapy is closer to practical use than gene therapy." Simons 2000, Post 2001 Most preliminary papers reported 
favorable results in treated patients. But a decade later, reviews concluded that neither of these two approaches showed unequivocal clinical benefit in double-blind, randomized placebo-

control trials. Khurana 2005, Simons 2005 "Inadequate duration of exposure to the angiogenic agent" may have limited its effectiveness. Gupta 2009 Another weakness in the clinical trials may have been the assumption that a single factor would be effective. ${ }^{\text {Zhang } 2009}$ These two considerations will be discussed later.

\subsection{Skeletal muscle studies in animals}

Ligation of a femoral artery in the hind limb of laboratory animals simulates lower leg muscle weakness in older persons. Table $6 \mathrm{~A}$ summarizes 5 such studies in mice, rats, and rabbits showing increased hind limb vascularity $(\uparrow \mathrm{CD})$ with angiogenic treatment. Table 6B concerns 8 reports showing increased microcirculation (and healing) after the application of AG factors in other experimental situations -- bone graft, wound repair, and sponge/gel implants.

\subsection{Skeletal muscles studies in people}

Post et al. noted the scarcity of clinical studies using AG factors in persons with peripheral vascular disease. ${ }^{\text {Post } 2001}$ Nor have I found any reports examining the effect of recombinant (r) angiogenic factors on the muscle weakness and sarcopenia of elderly persons.

The closest work is that by Lederman et al. showing the benefit of recombinant FGF-2 on intermittent claudication (IC). ${ }^{\text {Lederman }} 2002$ Patients with limited walking tolerance caused by infra-inguinal atherosclerosis received bilateral femoral artery infusions of three types: 1) placebos on Days $1 \& 30,2)$ rFGF-2 on Day $1 \&$ placebo on Day 30, 3) recombinant acidic FGF on both Days $1 \&$ 30. Exercise tolerance was measured using a standardized Gardner treadmill 
protocol. On Day 90 walking times in minutes were found to be increased from baseline values in the three groups as follows: $0.97 \mathrm{~min}(5.32 \rightarrow 6.29), 1.95 \mathrm{~min}(5: 15 \rightarrow 7.10)$, and $1.77 \mathrm{~min}$ $(5.81 \rightarrow 7.58)$, respectively. Two infusions of r-FGF-2 thirty days apart (the $3^{\text {rd }}$ treatment type) appeared less beneficial than a single injection only because that group had a higher baseline value $(5.81 \mathrm{~min}$.$) . The final assessment included 174$ patients. Sixteen others were eliminated because of adverse events, including renal abnormalities (proteinuria). The maximum tolerated dose was $30 \mu \mathrm{g} / \mathrm{kg}$. Higher levels induced acute hypotension. This study is valuable for highlighting the placebo effect and identifying untoward effects from rFGF-2.

\section{Angiogenic factors}

Of primary concern for treating muscle weakness in the aged would be selecting a therapeutic regimen. Simons concluded that in previous cardiac studies the choices of AG agents had "little physiological rationale" but instead rested on the availability of certain growth factors and the selection of those with less risk of side effects. Simons 2005 Again, useful information for selecting a particular treatment may be gleaned from the past clinical and laboratory studies -- notably, safe levels of these agents for people.

\subsection{Single agents}

Human trials to date have employed single agents - e.g., VEGF Vale 1999, Gibson 1999, Henry 1999, 2003 , FGF-1 Schumacher 1998 , and FGF-2. Laham 1999, 2000, Unger 2000 These and other factors are listed below, followed by brief abstracts of animal studies illustrating their use in therapeutic angiogenesis. 


\subsubsection{VEGF}

Of the six members of this family, three (VEGF-A, -B, \& -E) and PIGF (placental growth factor) act preferentially on vascular endothelial cells. VEGF "maintains its position as the most critical driver of vascular formation." Yancopoulos 2000 VEGF-1 and VEGF-D ${ }^{\Delta \mathrm{N} \Delta \mathrm{C}}$ have the strongest AG effect on skeletal muscles. Rissanen 2003

Takeshita et al. prepared rabbits with ischemia in one hind limb and injected a 500-5000 $\mu \mathrm{g}$ bolus of VEGF 165 over one minute in the ipsilateral iliac artery on Day 10 after ligation of the femoral artery. They found increased vascularity in the muscles of the treated leg by Day 30 but no additional increase later. Takeshita 1994 Rivard et al. followed the same procedure using a $500 \mu \mathrm{g}$ bolus of VEGF165 and found increased capillary density on Day 40 after surgery in treated rabbits, both young and old but somewhat less in the old ones. Rivard 1999: Fig 5G The latter authors regarded VEGF as "the pivotal cytokine deficiency responsible for impaired angiogenesis."

\subsubsection{FGF}

Of the 23 or so members of this group, FGF-1 (acidic FGF, aFGF) and FGF-2 (basic FGF, bFGF) are prototypes which are "preferentially implicated in angiogenesis." Friesel 1995, Post 2001 The most studied member, bFGF, has a broad spectrum of target cells - endothelial cells, smooth muscle cells, and fibroblasts. Friesel 1995

Baffour et al. examined bFGF in the ischemic hind limb rabbit model. Three groups of rabbits received various intramuscular injections daily for 14 days - 17 rabbits being saline controls, 15 receiving $1 \mu \mathrm{g}$ bFGF, and 15 receiving $3 \mu \mathrm{g}$ bFGF. Day 14 angiograms of the treated limbs showed CDs in the three groups, respectively, of $36 \pm 10,69 \pm 15$, and $108 \pm 7$. Baffour 1992 
These data plus related work by Yang et al., Witzenbichler at al., and others are listed in Table 7A. Yang 1996, Witzenhichler 1998

\subsection{Agents in synergism}

Various investigators have assumed that the clinical administration of a single AG factor (e.g., VEGF) would be ineffective, since several or many may be necessary for a coordinated

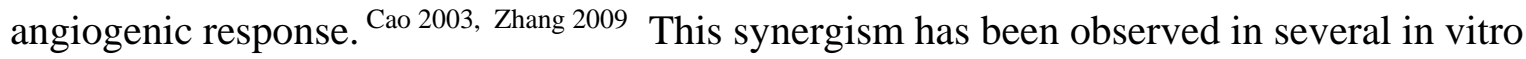
studies. Endothelial cells cultured within three-dimensional collagen gels and treated with VDGF and bFGF showed a synergistic effect on proliferation and cord formation - as additive effect greater than that of each agent alone. Pepper 1992, Goto 1993 Other examples of synergism are given below.

\subsubsection{Angiopoietin}

There are the four members of this family. Generalizing from many studies, Yancopoulos et al. wrote that Ang-1 acts synergistically with VEGF to promote vessel stability, while Ang-2 has the opposite effect. Yancopoulos 2000 Lloyd et al. cautioned that the ratio present may be crucial. Lloyd 2003

Peirce et al. examined the coordinated role of VEGF 165 and Ang-1 in dorsal skinfold window chambers surgically positioned on the backs of rats five days before Day 0 of the study. Slow release alginate beads contained either VEGF, Ang-1, or neither agent. A single bead was inserted in the visual field of each chamber on Day 0 and replaced on Day 7 . The chamber with a VEGF bead on Day 0 and control beads on Day 7 showed increased CD on Days 7 and 14 but not 21. The chamber with VEGF bead on Day and Ang-1 on day 7 showed increased CD on 
Days 7, 14, and 21, thus indicating that Ang-1 "promote[d] vessel stabilization and maturation." Peirce 2004

\subsubsection{Platelet derived growth factor.}

There are three isoforms of PDGF: AA, AB, and BB. In an ischemic hind limb model in rats, Zhang et al. found that PDGF-AB + FGF-2 yielded stable capillary growth, while PDGF$\underline{\mathrm{AA}}+\mathrm{FGF}-2$ did not. ${ }^{\text {Zhang }} 2009$

Cao et al. used a Matrigel pellet model, in which heparin-Sepharose beads containing one or two factors were inserted subcutaneously into mice and after two weeks retrieved and examined microscopically for vessel formation. Cao 2003 They found that PDGF-BB + FGF-2 elicits angiogenesis greater than the sum of the separate effect of both agents, while PDGF-BB +

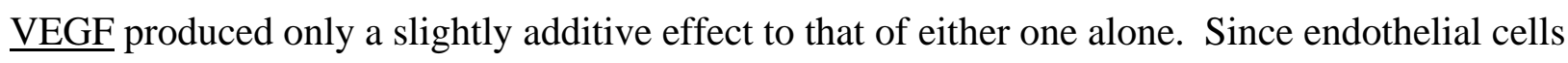
delineate the capillary lumen, while mural cells (pericytes and smooth muscle cells) stabilize it, the authors inferred that these two separate functions are controlled by different AG factors - the former by FGF-2 or VEGF and the latter by PDGF. The above four reports show that stable angiogenesis was produced with the appropriate combinations of factors.

\subsection{Further considerations}

Most clinical trials of the past several decades have employed only one agent. Single factor therapy for treating myocardial insufficiency has occasioned few or no complications. Henry 2000, Celletti 2001, Epstein 2001 But Yancopoulos et al. and other investigators have warned that the administration of "a single growth factor to reconstitute a vascular bed is somewhat naive and even misguided." Yancopoulos 2000, Henry 2000 Here the authors may have had in mind VEGF's 
original name, "vascular permeability factor," the risk of internal bleeding, and the stabilizing effect of Ang2 on VEGF. While this risk must be kept foremost in mind, an additional consideration explained below may qualify the above warning in the case of muscle weakness of the aged.

In older animals and people the levels of certain angiogenic factors are reduced in various tissues (muscle, brain, heart), but there is no evidence that all factors involved in producing the coordinated response of angiogenesis are reduced equally. Returning a deficient one to the earlier, youthful level might be sufficient if other participating factors are still available in tissue sites. Based on this assumption and in lieu of the few complications reported in numerous clinical trials with VEGF and FGF, replacing a single waning factor might be safe and effective in ameliorating general muscle weakness of old age. But this consideration still acknowledges the theoretical risk from long term treatment - i.e., longer than past clinical trials.

\section{Various routes for therapeutic angiogenesis}

Studies aimed at returning AG factors in muscles to normal, healthy levels would likely continue for many years - for the rest of an aged person's life. Dor 2002, Annex 2005, Ferrara 2005, Gupta 2009, Roy 2010 If therapeutic angiogenesis were found to be effective in preliminary trials, then the wide spread use of this method would be most feasible if it involve the self-administration of the AG factor. Intravenous and intramuscular routes are not convenient and disliked by many subjects. Agents ingested would be destroyed through acid/enzymatic breakdown in the gastro-intestinal tract. Alternative routes involving absorption via the nose, lung, cheek, or tongue avoid the GI destruction and first pass metabolism in the liver and would be preferable to injections by most subjects. (Ophthalmic, vaginal, and rectal routes are not considered here.) 
An obstacle at the four alternative sites is the absorption of macromolecules across lipidrich epithelial cell membranes into the circulation. Such absorption is inversely related to a protein's molecular weight - i.e., being less for large proteins, such as bFGF (17 kDa) and VEGF (42 kDa). Molecular weights are given for most of the AG factors noted below. Ways of overcoming the weight problem are discussed in Section 10.1.

\subsection{Nose}

Some sense of the absorption of various size macromolecules across mucous membranes into the circulation can be gleaned from the following examples. Intranasal (i.n.) administration of oxytocin $(1.0 \mathrm{kDa})$ led to its appearance in the plasma for up to two hours. Gossen 2012, Striepens 2013 Numerous investigators have determined blood levels of immunoreactive insulin given by this route. Pontiroli 1989: Table 1 Insulin $(5.8 \mathrm{kDa})$ administered i.n. reduced blood glucose levels, thus inferring the hormone's bioavailability in the systemic circulation. ${ }^{\text {Pontiroli } 1992}$ In normal subjects, an i.n. spray of insulin plus $\mathrm{Na}$ glycogluconate produced a serum insulin level 4-times higher than a spray with insulin alone. Pontiroli 1987: interpr. from Fig. 1 Thorne et al. found rising levels of $\left[{ }^{125}\right]$ insulin-like growth factor-1 $(7.65 \mathrm{kDa})$ in the blood of rats 23 minutes after i.n. treatment. At 21 minutes the level of the above ILGF-1 was $0.48 \mathrm{nM}$ in the blood and $0.15 \mathrm{nM}$ in the deltoideus muscle. Thorne 2004: Table 1 Vitkun et al. delivered interferon $\beta$-1a (20 kDa) by nasal spray to male subjects and found $20 \%$ bioavailability in blood samples. Vitkun 2004 The possible administration of AG factors (17-45 kDa) intranasally to senile dementia patients was raised in two earlier papers. The use of a tobacco-free snuff was suggested there. Ambrose 2013, 2015A

\subsection{Lungs}


The potential advantages of pulmonary delivery of macromolecular proteins are the lungs' large absorptive area, extensive vasculature, easily permeable membrane, and low enzyme activity Patton 1992, Liu 1993 Wigley et al. administered insulin to diabetic patients during a 5-minute nebulization period and found that $10 \%$ had been absorbed into the plasma. Wigley 1971 Liu et al. reported that intratracheal instillation into rat lungs of the sodium dimer $(11.6 \mathrm{kDa})$ or the zinc hexamer $(34.8 \mathrm{kDa})$ of insulin led to the drug's absorption as reflected in reduced blood glucose levels. The exact form of insulin (monomeric or multimeric) in the blood was not determined. The effect on blood glucose levels was similar whether the insulin preparation was entrapped in or merely accompanied by liposomes. Aerosol administration was judged to yield “comparable" results. Liu1993

\subsection{Buccal cheek}

The buccal mucosa is less permeable than the nasal mucosa, but most elderly subjects would probably prefer the former as a therapeutic route. Merkle 1991 Three types of adhesive buccal vehicles provide intimate contact with mucous epithelium: tablets, viscous gels, and patches. Merkle 1991 Boddie et al. employed buccal tablets made of muco-adhesive polymers, which protect against degradation by peptidases in the saliva. Boddie 1990

I have not found articles about enhancing absorption of AG factors with various adjuvants, but this approach is suggested by positive results of studies on other large molecules.

Buccal adjuvants have included bile acids, fatty acids (e.g., myristate), and sugar esters. Merkle 1991 Nakada et al. reported that deoxycholate, turoglycocholate, quillajasaponin, myristate, and sugar esters promoted absorption of human calcitonin $(3.4 \mathrm{kDa})$ via buccal mucosa of rats. Nakada 1988 Merkle et al. cited studies with the above adjuvants showing increased buccal and sublingual 
absorption of the following proteins: oxytocin $(1 \mathrm{kDa})$, calcitonin $(3.4 \mathrm{kDa})$, insulin $(5.8 \mathrm{kDa})$, interferon $(17 \mathrm{kDa})$, etc. For example, $5 \% \mathrm{Na}$ glycocholate added to insulin via buccal route $\rightarrow$ $25.5 \%$ of bioefficiency of the same dose of insulin given i.m. Aungst 1989

\subsection{Tongue}

The sublingual mucosa of the tongue underside is only $100-200 \mu \mathrm{m}$ thick, has fewer cell layers than the buccal mucosa, and is non-keratinized - all favoring better absorption. Shojaei 1998 In 1972 Sister Philomena Earle prepared 10 mg, I inch diameter tablets containing insulin $\mathrm{HCl}$ $(5.8 \mathrm{kDa})$ along with a binder and vasodilator (neither defined) for placement on or under the tongue. Using the tablet, she noted "a definite hypoglycemic reaction within 10 minutes" and a blood glucose estimate of $48 \mathrm{mg} / \mathrm{ml}$. Earle 1972 No baseline data were provided. Aungst et al. determined the absorption efficiency of insulin given by different routes to that by IM injection. The rank order of absorption was rectal >nasal > buccal > sublingual. Inclusion of $\mathrm{Na}$ glycocholate to the insulin greatly increased absorption with the nasal route being the highest at $46.8 \%$ and sublingual being $12 \%$. Aungst 1988

\section{Other issues in therapeutic angiogenesis}

Of theoretical concern is whether exogenously administered AG factors could correct a local deficiency in muscles. Affirmative evidence is present in Table 6A, which outlines five reports showing increased $\mathrm{CD}$ in the ischemic hind limbs of lab animals injected IV, IM, or subcutaneous with VEGF or bFGF. At issue is whether AG factors administered via the alternative routes (e.g., nasal, etc.) can pass into the circulation for access to distant muscles. 


\subsection{Absorption of AG factors}

In spite of their large size, perhaps AG factors $(17-45 \mathrm{kDa})$ can be modified to become more transferable without losing funtionality. Addition of methyl groups renders large molecule more lipophilic and thus more absorbable. Katrusiak 2011, Gazdik 2014

Surfactant enhancers in the form of various bile salts, etc. may facilitate this transfer. Gordon 1985, Aungst 1988, Wearley 1991, Lambert 2007 For example, Daugherty et al. administered recombinant methionyl human growth hormone (ca. $20 \mathrm{kDa}$ ) via the nasal mucosa of rats. The bioavailability in blood was $1 \%$ but rose to $7-8 \%$ in combination with bile salt sodium glycocholate. ${ }^{\text {Daugherty } 1988}$ But these permeation enhancers may cause irreversible damage to mucosal cells. Gordon 1985

Polycationic materials (poly-L-arginine/lysine) and chitosan may also enhance absorption of macromolecules. For example, in rat nasal studies, Miyamoto et al. found that adding poly-Larginine to a recombinant human granulocyte colony stimulating factor (rhG-CSF $=20 \mathrm{kDa}$ ) increased its bioavailability to $10 \%$. Miyamoto 2001 However, such enhancers may also be toxic to mucosal epithelium.

\subsection{Sustained treatment}

Since the lesser ailments of old age developed over many years, it seems unlikely that single bolus therapy could be effective. Treatment may need to be continuous and life-long. Many months may be required before beneficial clinical results become evident. In human trials sustained release delivery of an agent may be achieved with multivesicular liposome (DepoFoam). Angst 2006 Alginate capsules and nanoparticles have been used in various studies. Strand 2002, Peirce 2004, Roy 2010

The half-life of a protein in the circulation is determined by plasma proteases. ${ }^{\text {McGonigle }} 2012$ Takashita et al. reported unpublished data of N. Ferrara et al. listing the half life of VEGF as less 
than six minutes. Takashita 1994: 667 Protection of exogenous therapeutic agents can be obtained using liposomes and certain polymers. ${ }^{\text {Boddie } 1990}$ According to Katre et al., the free form of Insulin-like Growth Factor-1 survived in blood for less than one day but when incorporated into liposomes was sustained there for 5-7 days. Katre 1998

\subsection{Side effects}

Treatment continued over many years raises the threat of untoward mitogenesis inducing “angiogenic diseases" -- e.g., tumor growth, diabetic retinopathy, polyarthritis, psoriasis, etc. ${ }^{\text {Jain }}$ 1997, Epstein 2001, Carmeliet 2003 Also, there has been concern that angiogenic therapy may promote the growth and rupture of atheromatous plaques leading to angina and myocardial infarcts. Flugelman 1993, Kornowski 2000, Simons 2000, Celletti 2001, Moulton 2001 Recognizing untoward side effects is one purpose of clinical trials. Finding ways to avoid and correct them is the later challenge.

\section{Summary of Part II}

In contrast to Part I of this essay, which focused on age-linked decline of AG factors with aging, there are the numerous studies in regular (not aged) mice and rats showing that levels of endogenous VEGF are increased in the immediate areas of experimentally generated cerebral infarcts or surgically induced focal cerebral ischemia. These studies were identified in references \#130-138 in an earlier paper. Ambrose 2015A Thus under some circumstance, angiogenesis is naturally induced locally.

There is a growing consensus that the "induction of angiogenesis is a promising therapeutic approach ... to improving vascular function ... in aging patients." Lähteenvuo 2014. 
This expectation has not yet been realized for relieving weakened muscles of aged persons but has been amply demonstrated in laboratory animals. Various angiogenic factors administered to ischemic hind limbs of mice, rats, and rabbits have produced increased vascularity in the muscles there (Table 6A). Local application of AG factors to bone transplants, surgical wounds, and inserted sponges have likewise led to increased local vascularity (Table 6B).

The most impressive support to the idea of therapeutic angiogenesis has been in the brain. Discussed elsewhere are the clinical studies by Harry S. Goldsmith, who transposed the intact pedicled omentum from persons with Alzheimer's disease (AD) onto the surface of their brain. Ambrose 2015A, Goldsmith 2014 These pedicles, which contain high levels of VEGF, release this factor onto the cerebral surface, where it is absorbed into the parenchyma. ${ }^{\text {Zhanga } 1997}$ Goldsmith recently reviewed 25 such operations on advanced $\mathrm{AD}$ patients and reported that six showed no improvement, ten showed slight improvement, and "nine demonstrated marked cognitive increases." Goldsmith 2014 Of concern here is whether the positive results Goldsmith obtained in some AD patients with omentum grafts can be replicated for muscle weakness of old age by the administration of angiogenic factors.

As discussed earlier in Part I, muscle weakness from age-associated sarcopenia may have one or more possible causes -- 1) waning angiogenesis, 2) the temporal decline of muscle stem cells capable of "life-long maintenance and repair of myofibrils," Carlson 2008 and 3) a deficiency of certain hormones (e.g., testosterone). In spite of an incomplete understanding of the interplay of these possible causes, evidence supports considering the treatment of the muscle weakness of old age with therapeutic angiogenesis.

Edelberg and Reed began an article in 2003 with "Angiogenesis is impaired in aged tissues." Edelberg 2003 Another review like the present essay reaffirming this well documented 
observation would seem unnecessary except for the fact that therapeutic angiogenesis has yet to be pursued in the relief of the lesser ailments of old age and the senile dementias.

\section{Conclusions}

In this essay, old age is viewed as a deficiency state in which muscle weakness and memory loss may be due in part to a reduced microcirculation secondary to the age-linked decline of angiogenic factors. Waning stem cells and lower hormone levels may also exert a weakening effect on muscles via diminished angiogenesis. Senile dementias may be a long term consequence of the decline of angiogenic cytokines in the brain along with other possible influences. This general decline is analogous to that of certain hormones whose blood and tissue levels fall with age. Again, other influences besides a waning angiogenesis may also contribute to aging. But correcting one influence (e.g., a reduced CD) may delay symptoms and signs of aging.

Therapeutic angiogenesis with recombinant AG factors seems an appropriate treatment to be considered for the lesser ailments of old age and also senile dementias and would be equivalent to administering testosterone, thyroxin, etc. to persons with the corresponding hormonal deficiencies. The beneficial effect of these agents may continue up to the time when other pathologies intervene, leading to death.

\section{End}




\section{FOOTNOTES}

Footnote \#1. Riddle et al. summarized three decades of studies on age-related changes in cerebral capillary density in human subjects and rats. They listed 14 reports of decreases and 7 of no decreases. Riddle 2003 An explanation of the latter results may be tissue shrinkage in aged brains, which was discussed in a previous paper. ${ }^{\text {Ambrose } 2015}$

Footnote \#2. Notch refers to receptor proteins in the wall of cells enabling two adjacent ones (e.g., myogenic stem cells) to interact mechanically. The name derives from notches in the wings of mutant fruit flies. Various notched phenotypes were correlated with mutant loci in the

flies' chromosome. Morgan 1917 A gene homologous to the Notch gene in Drosophila was found in patients with lymphoblastic leukemia. Ellisen 1991 The name Notch has subsequently been applied to a genetic pathway system later found in myogenic precursor cells of higher animals. 


\section{ACKNOWLEDGEMENTS}

I thank Dr. Jack de la Torre, University of Texas at Austin, for valuable comments about an early draft of this paper. I am greatly indebted for extensive bibliographic help to Mrs. Amanda Williams, staff librarian of the Medical Center Library, University of Kentucky. Finally, I acknowledge the continued support of I.S. Tray II.

\section{REFERENCES}

Adolfsson J., Ljungqvist A., Tornling G., Unge G., 1981. Capillary increase in the skeletal muscle of trained young and adult rats. J. Physiol. 310, 529-532.

Amaral S.L., Papanek P.E., Greene A.S., 2001. Angiotensin II and VEGF are involved in angiogenesis induced by short-term exercise training. Am. J. Physiol. Heart Circ. Physiol. 281, H1163-H1169.

Ambrose C.T., 2012. Neuroangiogenesis: a vascular basis for Alzheimer's Disease and cognitive decline during aging. J. Alzheimer's Dis. 32, 773-788.

Ambrose C.T., 2013. Alzheimer's Disease: the great morbidity of the $21^{\text {st }}$ century. Am. Sci. 101, 194-201.

Ambrose C.T., 2015. A therapeutic approach for senile dementias: neuroangiogenesis. J. Alzheimer's Dis. 43, 1-17.

Andersen P., 1975. Capillary density in skeletal muscle of man. Acta physiol. scand. 95, 203205.

Andersen P., Henriksson J., 1977. Capillary supply of the quadriceps femoris muscle of man: adaptive response to exercise. J. Physiol. 270, 677-690. 
Angst M.S., Drover D.R., 2006. Pharmacology of drugs formulated with DepoFoam: a sustained release drug delivery system for parenteral administration using multivesicular liposome technology. Clin. Pharm. 45, 1153-1176.

Annex B.H., Torgan C.E., Lin P., et al., 1998. Induction and maintenance of increased VEGF protein by chronic motor nerve stimulation in skeletal muscle. Am. J. Physiol. 2, H860H867.

Annex B.H., Simons M., 2005. Growth factor-induced therapeutic angiogenesis in the heart: protein therapy. Cardiovascular Res. 65, 649-655.

Arthur W., Vernon R., Sage H., Reed M. 1998. Growth factors reverse the impaired sprouting of micro vessels from aged mice. Microvasc. Res. 55, 260-270.

Atkinson R.A., Srinivas-Shankar U., Roberts S.A., et al., 2010. Effects of testosterone on skeletal muscle architecture in intermediate-frail and frail elderly men. J. Gerontology A Biol. Sci. Med. Sci. 65A, 1215-1219.

Aungst B.J., Rogers N.J., Shefter E., 1988. Comparison of nasal, rectal, buccal, sublingual and intramuscular insulin efficacy and the effects of a bile salt absorption promoter. J. Pharm. Exper. Therapeutics 244, 23-27.

Aungst B.J., Rogers N.J., 1989. Comparison of the effects of various transmucosal absorption promoters on buccal insulin delivery. Int'1. J. Pharmaceutics 53, 227-235.

Baffour R., Berman J., Garb J.L., et al., 1992. Enhanced angiogenesis and growth of collaterals by in vivo administration of recombinant basic fibroblast growth factor in a rabbit model of acute lower limb ischemia: dose-response effect of basic fibroblast growth factor. J. Vasc. Surg. 1, 181-191. 
Banai S., Jaklitsch M.T., Casscells W., et al., 1991. Effects of acidic fibroblast growth factor on normal and ischemic myocardium. Circulation Res. 69, 76-81.

Banai S., Jaklitsch M.T., Shou M., et al., 1994. Angiogenic-induced enhancement of collateral blood flow to ischemic myocardium by vascular endothelial growth factors in dogs. Circulation 89, 2183-2189.

Baumgartner R.N., Koehler K.M., Gallagher D., et al., 1998. Epidemiology of sarcopenia among the elderly in New Mexico. Am. J. Epidem. 147, 755-763.

Beck L.S., Chen T.L., Mikalauski P., Ammann A.J., 1990. Recombinant human transforming growth factor - Beta 1 (rhTGF- $\beta 1$ ) enhances healing and strength of granulation skin wounds. Growth Factors 3, 267-275.

Bhasin S., Storer T.W., Berman N., et al., 1996. The effects of supraphysiologic doses of testosterone on muscle size and strength in normal men. New England J. Med. 335, 1-7.

Bjorksten J., 1962. Aging: present status of our chemical knowledge. J. Am. Geriatrics Soc. $10,125-139$.

Boddé H.E., DeVries M.E., Junginger H.E., 1990. Mucoadhesive polymers for the buccal delivery of peptides, structure-adhesiveness relationships. J. Controlled Release 13, 225231.

Borkan G.A., Hults D.E., Gerzof S.G., et al., 1983. Age changes in body composition revealed by computed tomography. J. Gerontology 38, 673-677.

Brack A.S., Conboy M.J., Roy S., et al., 2007. Increased Wnt signaling during aging alters muscle stem cell fate and increases fibrosis. Science 317, 807-810.

Breen E.C., Johnson E.C., Wagner H., et al., 1996. Angiogenic growth factor mRNA responses in muscle to a single bout of exercise. J. Appl. Physiol. 81, 355-361. 
Brodal P.. Ingjer F., Hermansen L., 1977. Capillary supply of skeletal muscle fibers in untrained and endurance-trained men. Am. J. Physiol. 232, H705-H712.

Brown M.D., Cotter M.A., Hudlická L., Vrbová V., 1976. The effect of different patterns of muscle activity on capillary density, mechanical properties and structure of slow and fast rabbit muscles. Pflügers Arch. 361, 241-250.

Campisi J., 1996. Replicative senescence: an Old Lives’ Tale. Cell 84, 497-500.

Cao R., Brakenhielm E., Pawliuk R., et al., 2003. Angiogenic synergism, vascular stability and improvement of hind-limb ischemia by a combination of PDGF-BB and FGF-2. Nature Medicine 9, 604-613.

Carlson M.E., Hsu M., Conboy I.M., 2008. Imbalance between pSmad3 and Notch induces CDK inhibitors in old muscle stem cells. Nature 454, 528-532.

Carmeliet P., 2003. Angiogenesis in health and disease. Nature Medicine 9, 653-660.

Celletti F.L., Waugh J.M., Amabile P.G., et al., 2001. Vascular endothelial growth factor enhances atherosclerotic plaque progression. Nature Medicine 7, 425-429.

Chen Y., Fu L., Han Y., Teng Y., Sun J., Xie R., Cao J., 2012a. Testosterone replacement therapy promotes angiogenesis after acute myocardial infarction by enhancing expression of cytokines HIDF-1a and VEGF. European J. Pharm. 684, 116-124.

Chen J., Ortmeier S.B., Savinova O.V., et al., 2012b. Thyroid hormone induces sprouting angiogenesis in adult heart of hypothyroid mice through the PDGF-Akt pathway. J. Cell. Mol. Med. 16, 2726-2735.

Chen Z., Ye R., Goldman S.A., 2013. Testosterone modulation of angiogenesis and neurogenesis in the adult songbird brain. Neuroscience 239, 139-148. 
Chilibeck P.D., Paterson D.H., Cunningham D.A., Taylor A.W., Noble E.G., 1997. Muscle capillarization, $\mathrm{O}_{2}$ diffusion distance, and $\mathrm{VO}_{2}$ kinetics in old and young individuals. J. Appl. Physiol. 82, 63-69.

Coggan A.R., Spina R.J., King D.S., et al., 1992. Histochemical and enzymatic comparison of the gastrocnemius muscle of young and elderly men and women. J. Gerontology: Biolog. Sci. 47, B71-76.

Coggan A.R., Spina R.J., King D.S., et al., 1992. Skeletal muscle adaptations to endurance training in 60- to 70-yr-old men and women. J. Appl. Physiol. 72, 1780-1786.

Colcombe S.J., Kramer A.F., Erickson K.I., et al., 2004. Cardiovascular fitness, cortical plasticity, and aging. Proc. Natl. Acad. Sci. 101, 3316-3321.

Comfort A., 1974. The position of aging studies. Mechanisms of Ageing and Development 3, $1-31$.

Conboy I.M., Rando T.A., 2002. The regulation of Notch signaling controls satellite cell activation and cell fate determination in postnatal myogenesis. Developmental Cell 3, 397-409.

Conboy I.M., Conboy M.J., Smythe G.M., Rando T.A., 2003. Notch-mediated restoration of regenerative potential to aged muscle. Science 302, 1575-1577.

Conboy I.M., Conboy M.J., Wagers A.J., Girma E.R., Weissman I.L., Rando T.A., 2005. Rejuvenation of aged progenitor cells by exposure to a young systemic environment. Nature 433: 760-764. 
Croley A.N., Zwetsloot K.A., Westerkamp L.M., et al., 2005. Lower capillarization, VEGF protein, and VEGF mRNA response to acute exercise in the vastus lateralis muscle of aged vs. young women. J. Appl. Physiol. 99, 1872-1879.

Daugherty A.L., Liggitt H.D., McCabe J.G., Moore J.A., Patton J.S, 1988. Absorption of recombinant methionyl-human growth hormone (Met-hGH) from rat nasal mucosa. Intl. J. Pharmaceutics 45, 197-206.

Degens H., Turek Z., Hoofd L., van't Hof M.A., Binkhorst R.A., 1993. Capillarization and fibre types in hypertrophied m. plantaris in rats of various ages. Resp. Physiol. 94, 217226.

Dellian M. Witwer B.P., Salehi H.A., Yuan F., Jain R.K., 1996. Quantitative and physiological characterization of angiogenic vessels in mice. Am. J. Path. 149, 59-71.

Denis C., Chatard J-C., Dormois D., Linossier M-T., Geyssant A., Lacour J-R., 1986. Effects of endurance training on capillary supply of human skeletal muscle on two age groups (20 and 60 years). J. Physiol., Paris 81, 379-383.

Desjardins M., Berti R., Lefebvre J., Dubeau S., 2014. Aging-related differences in cerebral capillary blood flow. Neurobiology Aging 35, 1947-1955.

Ding Y-H., Li J., Zhou Y., Rafols J.A., Clark J.C., Ding Y., 2006. Cerebral angiogenesis and expression of angiogenic factors in aging rats after exercise. Current Neurovascular Res. $3,15-23$.

Dor Y., Djonov V., Abramovitch R., et al., 2002. Conditional switching of VEGF provides new insights into adult neovascularization and pro-angiogenic therapy. EMBO J 21, 1939-1947. 
Drubaix I., Giakoumakis A., Robert L., Robert A.M., 1998. Preliminary data on the agedependent decrease in basic fibroblast growth factor and platelet-derived growth factor in the human vein wall and in their influence on cell proliferation. Gerontology 44, 9-14.

Duc H.T., 2014. The biological time calendar. Biomedicine Aging Path. 4, 77.

Earle M.P., 1972. Experimental use of oral insulin. Israel J. Med. Sci. 8, 899-900.

Eisermann K., Broderick C.J., Bazarov A., Moazam M.M, Fraizer G.C., 2013. Androgen up-regulates vascular endothelial growth factor expression in prostate cancer cells via an Sp1 binding site. Molecular Cancer 12, 1-12.

Ellisen L.W., Bird J., West D.C., Soreng A.L., Reynolds T.C., Smith A.L., Sklar J., 1991. TAN-1, the human homolog of the Drosophila Notch gene, is broken by chromosomal translocations in T lymphoblastic neoplasms. Cell 66, 649-661.

Edelberg J.M., Reed M.J., 2003. Aging and Angiogenesis. Frontiers Biosci. 8, s1199-1209.

Eppley B.L., Doucet M., Connolly D.T., Feder J., 1988. Enhancement of angiogenesis by bFGF in mandibular bone graft healing in the rabbit. J. Oral Maxillofac. Surg. 46, 391398.

Epstein S.E., Kornowski R., Fuchs S., Dvorak H.F., 2001. Angiogenesis therapy. Amidst the hype, the neglected potential for serious side effects. Circulation 104, 115-119.

Faulkner J.A., Larkin L.M., Claffin D.R., Brooks S.V., 2007. Age-related changes in the structure and function of skeletal muscles. Clin. Exp. Pharm. Physiol. 34, 1091-1096.

Ferrando A.A., Sheffield-Moore M., Yeckel C.W., et al., 2002. Testosterone administration to older men improves muscle function: molecular and physiological mechanisms. Am. J. Physiol. Endocrinol. Metab. 282, E601-E607.

Ferrara N., Kerbel R.S., 2005. Angiogenesis as a therapeutic target. Nature 438, 967-974. 
Flugelman M.Y., Virmani R., Correa R., Yu Z-X., et al., 1993. Smooth muscle abundance and fibroblast growth factors in coronary lesions of patients with nonfatal unstable angina. Circulation 88, 2493-2500.

Friesel R.E., Maciag T., 1995. Molecular mechanisms of angiogenesis: fibroblast growth factor signal transduction. FASEB J. 9, 919-925.

Frontera W.R., Hughes V.A., Fielg R.A., Fiatarone M.A., Evans W.J., Roubenoff R., 2000. Aging of skeletal muscle: a 12-yr longitudinal study. J. Appl. Physiol. 88, 1321-1326.

Gavin T.P., Spector D.A., Wagner H., Breen E.C., Wagner P.D., 2000. Nitric oxide synthase inhibition attenuates the skeletal muscle VDGF mRNA response to exercise. J. Appl. Physiol. 88, 1192-1198.

Gavin T.P., Ruster R.S., Carrithers J.A., et al., 2007. No difference in the skeletal muscle angiogenic response to aerobic exercise training between young and aged men. J. Physiol. 58.5, 231-239.

Gazdik M., O'Neill M.T., Lopaticki S., Lowes K.N., et al., 2014. The effect of N-methylation on transition state mimetic inhibitors of the Plasmdium protease, plasmepsin V. Med. Chem. Comm. 00, 1-3.

Gibson M.C., Simons M., Giodano F.J., Henry T.D., et al., 1999. Magnitude and location of new angiographically apparent coronary collaterals following intravenous VEGF administration. J. Am. Col. Cardiology Abstracts 384A.

Goldsmith H.S., 2014. Benefit of omental blood flow in Alzheimer's disease: effect on deteriorating neurons. J. Alzheimer's Dis. 42, S277-S280.

Gordon G.S., Moses A.C., Silver R.D., Flier J.S., Carey M.C., 1985. Nasal absorption of insulin: enhancement by hydrophobic bile salts. Proc. Natl. Acad. Sci. 82, 7419-7423. 
Gossen A., Hahn A., Westphal L., Prinz S., Schultz R.T., Gründer G., Spreckelmeyer K.N., 2012. Oxytocin plasma concentrations after single intranasal oxytocin administration - a study in healthy men. Neuropeptides 46, 211-215

Goto F., Goto K., Weindel K., Folkman J., 1993. Synergistic effects of vascular endothelial growth factor and basic fibroblast growth factor on the proliferation and cord formation of bovine capillary endothelial cells within collagen gels. Lab Invest 69, 508-517.

Greenhaigh D.G., Sprugel K.H., Murray M.J., Ross R., 1990. PDGF and FGF stimulate wound healing in the genetically diabetic mouse. Am. J. Path. 136, 1235-1246.

Gupta R., Tongers J., Losordo D.W., 2009. Human studies of angiogenic gene therapy. Circulation Res. 105, 724-736.

Gustafsson T., Bodin K., Sylvén C., Gordon A., Tyni-Lenné R., Jansson E., 2001. Increased expression of VEGF following exercise training in patients with heart failure. Europ. J. Clin. Invest. 31, 362-366.

Gustaffson T.. Puntschart A., Kaijser L., Jansson E., Sundberg C.J., 1999. Exerciseinduced expression of angiogenesis-related transcription and growth factors in human skeletal muscle. Am. J. Physiol. 276, H679-H685.

Gustafsson T., Knutsson A., Puntschart A., et al., 2002. Increased expression of vascular endothelial growth factor in human skeletal muscles in response to short-term onelegged exercise training. Europ. J. Physiol. 442, 752-759.

Haidet G.C., Parsons D., 1991. Reduced exercise capacity in senescent beagles: an evaluation of the periphery. Am. J. Physiol. 260, H173-H182.

Hall G.S., 1922. The contribution of biology and physiology, in: Hall G.S., Senescence: the last half of life. D. Appleton, New York, pp. 248-318. 
Hang J., Kong L., Gu J-W., Adair TH., 1995. VEGF gene expression is upregulated in electrically stimulated rat skeletal muscle. Am. J. Physiol. 269, H1827-H1831.

Hather B.M., Tesch P.A., Buchanan P., Dudley G.A., 1991. Influence of eccentric actions on skeletal muscle adaptations to resistance training. Acta Physiol. Scand. 143, 177-185.

Hayflick L., 1975. Current theories of biological aging. Federation Proc. 34, 9-13.

Henry T.D., Rocha-Singh K., Isner J.M., Kerelakaes D.J., et al., 1998. Results of intracoronary recombinant human vascular endothelial growth factor (rhVEGF) administration trial. J. Am. Col. Cardiol. Abstr. 65A.

Henry T.D., Annex B.H., Azrin M.A., McKendall G.R., et al., 1999. Double blind, placeba controlled trial of recombinant human vascular endothelial growth factor - The VIVA Trial. J. Am. Coll. Cardiol. 33, 384A.

Henry T.D., Abraham J.A., 2000. Review of preclinical and clinical results with vascular endothelial growth factors for therapeutic angiogenesis. Curr. Interventional Cardiology Reports 2, 228-241.

Henry T.D., Annex B.H., McKendall G.R., et al., 2003. Vascular endothelial growth factor in ischemia for vascular angiogenesis. Circulation 107, 1359-1365.

Hepple R.T., Mackinnon S.L.M., Goodman J.M., Thomas S.G., Plyley M.J., 1997. Resistance and aerobic training in older men; effects of $\mathrm{VO}_{2 \text { peak }}$ and the capillary supply to skeletal muscle. J. Appl. Physiol. 82, 1305-1310.

Hillman C.H., Pontifex M.B., Castelli D.M., Khan N.A., et al., 2014. Effects of the FITKids randomized controlled trial on executive control and brain function. Pediatrics 134, 1063-1071. 
Hudlicka O., Dodd L., Renkin E.M., Gray S.D., 1982. Early changes in fiber profile and capillary density in long-term stimulated muscles. Am. J. Physiol. 243, H528-H535.

Hudlicka O., Milkiewicz M., Cotter M.A., Brown M.D., 2002. Hypoxia and expression of VEGF-A protein in relation to capillary growth in electrically stimulated rat and rabbit skeletal muscles. Expl. Physiol. 87.3, 373-381.

Iemitsu M., Maeda S., Jesmin S., Otsuki T., Miyauchi T., 2006. Exercise training improves aging- induced downregulation of VEGF angiogenic signaling cascade in hearts. Am. J. Physiol. Heart Circ. Physiol. 291, H1290-H1298.

Ingjer F., Brodal P., 1978. Capillary supply of skeletal muscle fibers in untrained and endurance-trained women. Europ. J. appl. Physiol. 38, 291-299.

Ingjer F., 1979. Effects of endurance training on muscle fiber ATP-ase activity, capillary supply and mitochondrial content in man. J. Physiol. 294, 419-432.

Isaac K.R., Anderson B.J., Alcantara A.A., Black J.E., Greenough W.T., 1992. Exercise and the brain: angiongenesis in the adult rat cerebellum after vigorous physical activity and motor skill learning. J. Cerebral Blood Flow Metab. 12, 110-11.

Jain R.K., Schlenger K., Höckel M., Yuan F., 1997. Quantitative angiogenesis assays: progress and problems. Nature Medicine 3, 1203-1208.

Joseph I.B.J.K., Nelson J.B., Denmeade S.R., Isaacs J.T., 1997. Androgens regulate vascular endothelial growth factor content in normal and malignant prostatic tissue. Clin. Cancer Res. 3, 2507-2511.

Kang D-H., Anderson S., Kim Y-G., Mazzalli M., Suga S-i., et al., 2001. Impaired angiogenesis in the aging kidney: vascular endothelial growth factor and thrombospondin-1 in renal disease. Am. J. Kidney Dis. 37, 601-611. 
Kanno S., Oda N., Abe M., Sachiko S., et al., 1999. Establishment of a simple and practical procedure applicable to therapeutic angiogenesis. Circulation 99, 2682-2687.

Katre N.V., Asherman J., Schaefer H., Hora M., 1998. Multivesicular liposome (DepoFoam) technology for the sustained delivery of insulin-like growth factor-1(IGF-1). J Pharmaceut. Sci. 87, 1341-1346.

Katrusiak A., Piechowiak P., Katrusiak A., 2011. Synthesis, tautomeric forms, specific intermolecular interactions, and lipophilicity of methylated 6-hydroxypyridzine-3carboxylic acid and its 4,5-dihydro analogs. J. Mol. Structure 998, 84-90.

Khurana R., Simons M., Martin J.F., Zachary I.C., 2005. Role of angiogenesis in cardiovascular disease: a critical appraisal. Circulation 112, 1813-1824.

Kornowski R., Fuchs S., Leon M.B., Epstein S.E., 2000. Delivery strategies to achieve therapeutic myocardial angiogenesis. Circulation 101, 454-458.

Kowald A., Kirkwood T.B.L., 1996. A network theory of ageing: the interactions of defective mitochondria, aberrant proteins, free radicals and scavengers in the ageing process. Mutation Res. 316, 209-236.

Laham R.J., Rezaee M., Post M., Sellke F.W., Braeckman R.A., Hung D., Simons M., 1999. Intracoronary and intravenous administration of basic fibroblast growth factor: myocardial and tissue distribution. Drug Metab. Disposition 27, 821-826.

Laham R.J., Chronos N.A., Pike M., Leimbach M.E., et al., 2000. Intracoronary basic fibroblast growth factor (FGF-2) in patients with severe ischemic heart disease: results of a Phase I open-label dose escalation study. J. Am. Coll. Cardiol. 36, 2132-2139.

Lähteenvuo J., Rosenzweig A., 2014. Effects of aging on angiogenesis. Circulation Res. 110, $1252-1263$. 
Lambert W.J., 2007. Drug delivery: what the future holds. BioPharm. International 20, 32-39.

Lamberts S.W.J., van den Beld A.W., van der Lely A-J., 1997. The endocrinology of aging. Science 278, 419-424.

Lederman R.J., Mendelsohn F.O., Anderson R.D., et al., 2002. Therapeutic angiogenesis with recombinant fibroblast growth factor-2 for intermittent claudication (the TRAFFIC study): a randomized atrial. Lancet 359, 2053-2058.

Leosco D., Rengo G., Iaccarino G., Sanzari E., et al., 2007. Prior exercise improves agedependent vascular endothelial growth factor downregulation and angiogenesis responses to hind-limb ischemia in old rats. J. Gerontology: Biolog. Sci. 62A, 471-480.

Lin, J., Lopez E.F., Jin Y., Remmen H.V., Bauch T., Han H-C., Lindsey M.L. 2008 Agerelated cardiac muscle sarcopenia: combing experimental and mathematical modeling to identify mechanisms. Exp. Gerontol., 43, 296-306.

Liu F-y., Shao Z., Kildsig D.O, Mitra A.K., 1993. Pulmonary delivery of free and liposomal insulin. Pharmaceutical Res. 10, 228-232.

Liu X., Zheng N., Shi Y-N., Yuan J., Li L., 2014. Thyroid hormone induced angiogenesis through the integrin $\alpha v \beta 3 /$ protein kinase D/histone deacetylase 5 signaling pathway. J. Molecular Endocrinology 52, 245-254.

Lloyd P.G., Prior B.M., Yang H.T., Terjung R.L., 2003. Angiogenic growth factor expression in rat skeletal muscle in response to exercise training. Am. J. Physiol. Heart Circ. Physiol. 284, H1668-H1678.

Luidens M.K., Mousa SA., Davis FB., Lin H-Y., Davis P.J., 2010. Thyroid hormone and angiogenesis. Vascular Pharm. 52, 142-145.

Marx J.L., 1979. Aging research (I): cellular theories of senescence. Science 186, 1105-1107. 
McGee G.S., Davidson J.M., Buckley A., Sommer A., et al., 1988. Recombinant basic fibroblast growth factor accelerates wound healing. J. Surg. Res. 45, 145-153.

McGonigle P., 2012. Peptide therapeutics for CNS indications. Biochem. Pharm. 83, 559-566.

Merkle H.P., Anders R., Wermerskirchen A., Raehs S., Wolany G., 1991. Buccal routs of peptide and protein drug delivery, in: VHL Lee, ed., Peptide and Protein Drug Delivery, Marcel Decker, New York, pp 545-570.

Milkiewicz M., Brown M.D., Egginton S., Hudlicka O., 2001. Association between shear stress, angiogenesis, and VEGF in skeletal muscles. Microcirculation 8, 229-241.

Miyamoto M., Natsume H., Satoh I., Ohtake K., et al., 2001. Effect of poly-L-arginine on the nasal absorption of FITC-dextran of different molecular weights and recombinant human granulocyte colony-stimulating factor (rhG-CSF) in rats. Int'1. J. Pharmaceutics 226, $127-138$.

Morales D.E., McGowan K.A., Grant D.S., Maheshwari S., et al., 1995. Estrogen promotes angiogenic activity in human umbilical vein endothelial cells in vitro and in a murine model. Circulation 91, 755-763

Morgan T.H., 1917. The theory of the gene. American Naturalist 51, 513-544.

Moulton K.S., 2001. Areplaque angiogenesis and atherosclerosis. Current Atherosclerosis Reports 3, 225-233.

Mousa S.A., Lin H-Y., Tang HY., Hercbergs A., Luidens M.K., Davis P.J., 2014. Modulation of angiogenesis by thyroid hormone and hormone analogues: implications for cancer management. Angiogenesis 17, 463-469.

Nakada Y., Awata N., Nakamichi C., Sugimoto I., 1988. The effect of additives on the oral mucosal absorption of human calcitonin in rats. J. Pharmacobio-Dyn. 11, 395-401. 
Pafenbarger R.S., Hyde R.T., Wing A.L., Hsieh C-c., 1986. Physical activity all-cause mortality, and longevity of college alumni. New England J. Med. 314, 605-613.

Patton J.S., Platz R.M., 1992. Routes of delivery: case studies. (2) Pulmonary delivery of peptides and proteins for systemic action. Adv. Drug Delivery Reviews 8, 179-196.

Peirce S.M., Price R.J., Skalak T.C., 2004. Spatial and temporal control of angiogenesis and arterialization using focal applications of VEGF 164 and Ang-1. Am. J. Physiol. Circ. Physiol. 286, H918-H925.

Pepper M.S., Ferrara N., Orci L., Montesano R., 1992. Potent synergism between vascular endothelial growth factor and basic fibroblast growth factor in the induction of angiogenesis in vitro. Biochem. Biophys. Res. Comm. 189, 824-831.

Pontiroli A.E., Alberetto M., Pajetta E., Calderara A., Pozaa G., 1987. Human insulin plus sodium glycocholate in a nasal spray formulation: improved bioavailability and effectiveness in normal subjects. Diabete \& Metabolisme (Paris) 13, 441-443.

Pontiroli A.E., Calderara A., Pozza G., 1989. Intransal drug delivery: potential advantages and limitations from a clinical pharamacokinetic perspective. Clin. Pharmacokinet. 17, 299-307.

Pontiroli A.E., 1992. Present situation of work with nasal and oral administration of insulin and glucagon in: Duchene, D. (ed), Buccal and Nasal Administration as an Alternative to Parenteral Administration: Minutes: European Symposium, Paris 10 \& 11 Dec. 1991, pp. 226-237

Post M.J., Laham R., Sellke F.W., Simons M., 2001. Therapeutic angiogenesis in cardiology using protein formulations. Cardiovascular Res. 49, 522-531. 
Puolakkainen P.A., Reed M.J., Gombotz W.R., et al., 1995. Acceleration of wound healing in aged rats by topical application of transforming growth factor- $\boldsymbol{\beta}_{1}$. Wound Rep. Reg. 3, 330-339.

Reed, M.J., Corsa A., Pendergrass W., Penn P., Sage E.H., Abrass I.B., 1998. Delayed angiogenesis is coincident with decreased levels of transforming growth factor $\boldsymbol{\beta} 1$ and Type 1 collagen. Am. J. Path. 152, 113-123.

Richardson R.S., Wagner H., Mudaliar S.R.D., et al., 1999. Human VEGF gene expression in skeletal muscle: effect of acute normoxic and hypoxic exercise. Am. J. Physiol. 277, H2247-H2252.

Riddle D.R., Sonntag W.E., Lichtenwalner R.J., 2003. Microvascular plasticity in aging. Ageing Res. Rev. 2, 149-168.

Rissanen T.T., Markkanen J.E., Gruchala M., Heikura T., et al., 2003. VEGF-D is the strongest angiogenic and lymphangiogenic effector among VEGFs delivered into skeletal muscle via adenoviruses. Circulation Res. 92, 1098-1106.

Rivard A., Fabre J-E., Silver M., Chen D., et al.. 1999. Age-dependent impairment of angiogenesis. Circulation 99, 111-120.

Roca J., Gavin T.P., Jordan M., Siafakas N., et al., 1998. Angiogenic growth factor mRNA response to passive and contraction-induced hyperperfusion in skeletal muscle. J. Appl. Physiol. 85, 1142-1149.

Roth G.S., 1979. Hormone receptor changes during adulthood and senescence: significance for aging research. Federation Proc. 38, 1910-1914. 
Roy R.S., Soni S., Harfouche R., Vasudevan P.R., et al., 2010. Coupling growth-factor engineering with nanotechnology for therapeutic angiogenesis. Proc. Natl. Acad. Sci. 107, 13608-13613.

Rubanyi G.M., Johns A., Kauser K., 2002. Effect of estrogen on endothelial function and angiogenesis. Vascular Pharm. 38, 89-98.

Ryan N.A., Zwetsloot K.A., Westerkamp L.M., et al., 2006. Lower skeletal muscle capillarization and VEGF expression in aged vs. young men. J. Appl. Physiol. 100, 178185.

Sadoun E., Reed M.J., 2003. Impaired angiogenesis in aging is associated with alterations in vessel density, matrix composition, inflammatory response, and growth factor expression. J. Histochem. Cytochem. 51, 1119-1130.

Schlenker E.H., Hora M., Liu Y., Redetzke R.A., Morkin E., Gerdes A.M., 2008. Effects of thyroidectomy, $\mathrm{T}_{4}$, and DITPA replacement on brain blood vessel density in adult rats. Am. J. Physiol. Regul. Integr. Comp. Physiol. 294, R1504-R1509.

Schumacher B.. Pecher P., von Specht B.U., Stegmann T.H., 1998. Induction of neoangiogenesis in ischemic myocardium by human growth factors. First clinical results of a new treatment of coronary heart disease. Circulation 97, 654-650.

Shojaei A.H., 1998. Buccal mucosa as a route for systemic drug delivery: a review. J. Pharm. Pharmaceut. Sci. 1, 15-30.

Sieveking D.P., Ng M.K.C., 2009. Cell therapies for therapeutic angiogenesis: back to the bench. Vascular Medicine 14, 153-166.

Sieveking D.P., Lim P., Chow R.W.Y., Dunn L.L., et al., 2010 . A sex-specific role for androgens in angiogenesis. J. Exp. Med. 207, 345-352. 
Sih R., Morley J.E., Kaiser F.E., Perry H.M., Patrick P., Ross C., 1997. Testosterone replacement in older hypogonadal men: a 12-month randomized controlled trial. J. Clin. Endo. Metab. 82, 1661-1667.

Simons M., Bonow R.O., Chronos N.A., Cohen D.J., et al., 2000. Clinical trials in coronary angiogenesis: issues, problems, consensus. Circulation 102, e73-e86.

Simons M., 2005. Angiogenesis: where do we stand now? Circulation 111, 1556-1566.

Sinha-Hikim I., Cornford M., Gaytan H., Lee M.L., Bhasin S., 2006. Effects of testosterone supplementation on skeletal muscle fiber hypertrophy and satellite cells in communitydwelling older men. J. Clin. Endo. Metab. 91, 3024-3033.

Skorjanc D., Jaschinski F., Heine G., Pette D., 1998. Sequential increases in capillarization and mitochondrial enzymes in low-frequency-stimulated rabbit muscle. Am. J. Physiol. 274, C810-C818.

Snyder P.J., Peachey H., Hannoush P., Berlin J.A., et al., 1999. Effect of testosterone treatment on body composition and muscle strength in men over 65 years of age. $\mathrm{J}$. Clin. Endoc. Metab. 84, 2647-2653.

Solerta S.B., Fioravantil M., 2002. Downregulation of vascular endothelial growth factor generation from immune cells in Alzheimer's disease. Neurobiology Aging 23 (suppl 1), S532.

Sordello S., Bertrand N., Plouet J., 1998. Vascular endothelial growth factor is up-regulated in vitro and in vivo by androgens. Biochem. Biophys. Res. Comm. 251, 287-290.

Strand B.L., Gaserod O., Kulseng B., Espevik T., Skjak-Baek G., 2002. Alginate-polyalginate microcapsules: effect of size reduction on capsule properties. J. Microencapsul 19, 615-630. 
Striepens N., Kendrick K.M., Hanking..fg V., et al., 2013. Scientific Reports 3, 1-5.

Strothart C.R., Simons D.J., Boot W.R., Kramer A.F., 2014. Is the effect of aerobic exercise on cognition a placebo effect? PLOS ONE 9, 1-7.

Swift M.E., Kleinman H.K., DiPietro L.A., 1999. Impaired wound repair and delayed angiogenesis in aged mice. Lab. Invest. 79, 1479-1487.

Takeshita S., Zheng L.P., Brogi E., Kearney M., et al., 1994. Therapeutic angiogenesis. A single intraarterial bolus of vascular endothelial growth factor augments revascularization in a rabbit ischemic hind limb model. J. Clin. Invest. 93, 662-670.

Tang K., Breen E.C., Gerber H-P., Ferrara N.M.A., Wagner P.D., 2004 Capillary regression in vascular endothelial growth factor-deficient skeletal muscle. Physiol. Genomics 18, 63-69.

Tateishi-Yuyama E., Matsubara H., Murohara T., et al., 2002. Therapeutic angiogenesis for patients with limb ischemia by autologous transplantation of bone-marrow cells: a pilot study and a randomized controlled trial. Lancet 360, 427-435.

Thompson J.A., Anderson K.D., DiPietro J.M., Zwiebel J.A., et al., 1988. Site-directed neovessel formation in vivo. Science 241, 1349-1352.

Thorne R.G., Pronk G.J., Padmanabhan V., Frey W.H., 2004. Delivery of insulin-like growth factor-1 to the rat brain and spinal cord along olfactory and trigeminal pathways following intranasal administration. Neuroscience 127, 481-496.

Tsuboi R., Rifkin D.B., 1990. Recombinant basic fibroblast growth factor stimulates wound healing in healing-impaired db/db mice. J. Exp. Med. 172, 245-251. 
Unge G., Carlsson S., Ljungqvist A., Tornling G., Adolfsson J., 1979. The proliferative activity of myocardial capillary wall cells in variously aged swimming-exercised rats. Acta path. microbial. scand. Section A, 187, 15-17.

Unger E.F., Goncalvaes L., Epstein S.E., Chew E.Y., et al., 2000. Effects of a single intracoronary injection of basic fibroblast growth factor in stable angina pectoris. Am. J. Cardiol. 85, 144-149

Urban R.J., Bodenburg Y.H., Gilkison C., Foxworth J., et al., 1995. Testosterone administration to elderly men increases skeletal muscle strength and protein synthesis. Am. J. Physiol. 269, e820-e826.

Vale P.R., Losordo D.W., Dunnington C.H., Lathi K., et al., 1999. Direct intramyocardial injection of VEGF results in effective gene transfer for patients with chronic myocardial ischemia. J. Am. Coll. Cardiol. 33, 384A.

van Praag H., Christie B.R., Sejnowski T.J, Gage F.H., 1999. Running enhances neurogenesis, learning, and long-term potentiation in mice. Proc. Natl. Acad. Sci. 96, $13427-13431$.

Verhaeg J., Milkiewicz M., Brown M.D., Egginton S., Hudlicka O., 2001. Proliferation of capillaries induced by electrical stimulation in relation to muscle fibre type in rats. $J$ Vasc Res 381, 409.

Viboolvorakul S., Patumraj S., 2014. Exercise training could improve age-related changes in cerebral blood flow and capillary vascularity through the upregulation of VEGF and eNOS. Biomed. Res. Int'1. 2014, 1-12. 
Vitkun S.A., Sileno A., Cimino L., Quay S.C., 2004. A comparative study of a nasal formulation of interferon Beta-1A versus Avonex ${ }^{\mathrm{R}}$ for injection. Neurology 62, A492A493.

Wagatsuma A., 2006. Effect of aging on expression of angiogenesis-related factors in mouse skeletal muscle. Expl. Gerontology 41, 49-54.

Wagers A.J., Conboy I.M., 2005. Cellular and molecular signatures of muscle regeneration: current concepts and controversies in adult myogenesis. Cell 122, 659-667.

Wagner P.D., Olfert I.M., Tang K., Breen E.C., 2006. Muscle-targeted deletion of VEGF and exercise capacity in mice. Resp. Physiol. Neurobiology 151, 159-166.

Wearley L.L., 1991. Recent progress in protein and peptide delivery by noninvasive routes. Critical Rev. Therapeutic Drug Carrier Systems 8, 331-394.

Weinert B.T., Timiras P.S., 2003. Physiology of Aging: theories of aging. J. Appl. Physiol. 95, 1706-1716.

Wigley F.M., Londono J.H., Wood S.H., Shipp J.C., Waldman R.H., 1971. Insulin across respiratory mucosae by aerosol delivery. Diabetes $20,552-556$.

Wittert G.A., Chapman I.M., Haren M.T, Mackintosh S., Coates P., Morley J.E., 2003. Oral testosterone supplementation increases muscle and decreases fat mass in healthy elderly males with low-normal gonadal status. J. Gerontology 58A, 618-625.

Witzenbichler B., Asahara T., Murohara T., Silver M., et al., 1998. Vascular endothelial growth factor-C (VEGF-C/VEGF-2) promotes angiogenesis in the setting of tissue ischemia. Am. J. Path. 153, 381-394.

Yancopoulos G.D., Davis S., Gale N.W., Rudge J.S., Wiegand S.J., Holash J., 2000.

Vascular-specific growth factors and blood vessel formation. Nature 407, 242-248. 
Yang H.T., Deschenes M.R., Ogilvie R.W., Terjung R.L., 1996. Basic fibroblast growth factor increases collateral blood flow in rats with femoral arterial ligation. Circulation Res. 79, 62-69.

Zhang J., Cao R., Zhang Y., Jia T., Cao Y., Wahlberg E ., 2009. Differential roles of PDGFR- $\boldsymbol{\alpha}$ and PDGFR- $\boldsymbol{\beta}$ in angiogenesis and vessel stability. FASEB J. 23, 153-163.

Zhang L., Cooper-Kuhn M.C., Nannmark U., Blomgren K., Kuhn H.G., 2010. Stimulatory effects of thyroid hormone on brain angiogenesis in vivo and in vitro. J. Cerebral Blood Flow \& Metabolism 30, 323-335.

End 
Table 1. Reduced Capillary Density in Muscles of Young vs. Aged Persons

1. Coggan 1992, Table 3 lateral gastrocnemius

-- capil. $/ \mathrm{mm}^{2}$, male

-- capil. $/ \mathrm{mm}^{2}$, female

2. Proctor 1995 , Table 3 vastus lateralis

-- capil. $/ \mathrm{mm}^{2}$

-- capil. contact/fiber IIA \& IIB

3. Chilibeck 1997, Table 3 lateral gastrocnemius

-- capil. $/ \mathrm{mm}^{2}$

4. Frontera 2000, Table 4

longitudinal study, men ( $\Delta 12 \mathrm{yrs})$

-- capil./fiber

5. Ryan 2006, Fig 2D (ex)

vastus lateralis

-- capil. $/ \mathrm{mm}^{2}$ vs. Type 1 fibers

\section{Young}

$\underline{24 \pm 1 \text { yrs. }}$

$308 \pm 16$

$328 \pm 19$

21-30 yrs.

$419 \pm 87$

$5.0 \pm 0.9$

25.9 yr., mean

$295 \pm 105$

$\underline{1985-6}$

$1.39 \pm 0.21$

19-25 yrs.

240 $\underline{\text { Aged }}$

$\underline{64 \pm 1 \mathrm{yrs} .}$ $228 \pm 13$

$248 \pm 12$

51-62 yrs. $390 \pm 41$

$3.9 \pm 0.8$

66.9 yr., mean $245 \pm 50$

$\underline{1997-8}$

$1.08 \pm 0.1$

$\underline{62-72 \text { yrs. }}$ 200 
Table 2. Reduced Capillary Density in Skeletal Muscles of Young vs. Aged Animals

1. Haidet 1991, Table 6 Beagle dogs, cap $/ \mu \mathbf{m}^{2}$

-- gastrocnemius

-- semitendinosus

Young

$\underline{2-3}$ yrs.

$886 \pm 49$

$895 \pm 41$

$959 \pm 47$

2. Degens 1993, Fig.4 (ex)* rat plantarus

-- capil. $/ \mathrm{mm}^{2}$

3. Rivard 1999, Fig. 5 (ex)*

-- mice hind limb, capil. $/ \mathrm{mm}^{2}$

-- rabbits hind limb, capil. $/ \mathrm{mm}^{2}$
$5 \mathrm{mo}$.

1000

12 wks.

710

$\underline{6-8 \mathrm{mo}}$

170

$\frac{4 \mathrm{mo} .}{590}$

750
Aged

10-14 yrs.

$718 \pm 31$

$658 \pm 31$

$805 \pm 52$

4. Leosco 2007, Fig. 3

rat hind limb, capil. $/ \mathrm{mm}^{2}$

-- untrained

-- trained

$\underline{25 \mathrm{mo}}$. 700

2 yrs.

350

$\underline{4-5 \mathrm{yrs}}$

130

* Data in some figures have been extrapolated from figures, as indicated by (ex). 
Table 3. Reduced Angiogenic Factors in Muscles of Young, Aged, \& AD Subjects

1. Drubaix 1998, Figs. 4,5 (ex ) $\mathrm{ng} / \mathrm{mg}$ DNA of saphenous vein wall -- bFGF

-- PDGF

\begin{tabular}{ccc} 
Young & \multicolumn{1}{c}{$\underline{\text { Aged }}$} \\
$\frac{20-40 \mathrm{yrs} .}{180}$ & $\frac{41-60 \mathrm{yrs} .}{70}$ & $\frac{61-82 \mathrm{yrs} .}{50}$ \\
70 & 45 & 30
\end{tabular}

2. Solerte 2002, abstract VEGF released, $\mathrm{pg} / \mathrm{ml}$

-- from monocytes

healthy (yrs. not stated)

296

$\frac{22-28 \mathrm{yrs}}{7.6}$

7.6

$19-25$ yrs.

1.0

-- VEGF 18s mRNA, at rest

-- VEGF 18s mRNA, 4 hrs after exercise 3.4

-- VEGF protein, at rest

1.05

-- VEGF protein, $4 \mathrm{hrs}$ after exercise

1.15
$\underline{\mathrm{AD} \& \mathrm{VAD}}$ 125

$\frac{60-85 \mathrm{yrs}}{3.2}$

3.2

$\frac{62-72 \mathrm{yrs}}{0.4}$

1.8

0.55

0.9

* Data in some figures have been extrapolated from figures in text, as indicated by (ex). 
Table 4. Reduced Angiogenic factors in Skeletal Muscles of Young vs. Aged Animals

1. Rivard 1999, Figs. 8A\&C

Young Aged

VEGF protein in ischemic muscle of rabbits $12 \mathrm{wks}$.

-- Western blot, Fig. 8A

-- immunostaining, Fig. $8 \mathrm{C}$

young level

2 yrs.

reduced

young level reduced

2. Wagatsuma 2006, Fig. 2 (ex)

gastrocnemius muscle of mice

$$
2.5 \mathrm{mo} \text {. }
$$

$22 \mathrm{mo}$.

-- VEGF

1.0

0.7

3. Swift 1999, Table 1

muscle wound homogenates of mice

-- VEGF ... before injury/wound day 5 day 7

-- FGF-2 ... before injury day 5 day 7

2-3 mo. not detectable 116

84

27

362

407
22-24 mo.

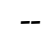

65

43

49

253

263 


\section{Table 5. Physiological Angiogenesis in Muscles}

5A. PHYSICAL EXERCISE ... $\uparrow=$ increase, $\downarrow=$ decrease $\ldots$ G20 = ca. age 20, G60 = ca. age 60

-. People ... 15 studies ... aerobic training and muscles

Andersen $1975,1977 \ldots \uparrow$ CD by $50 \%$

Brodal $1977 \ldots \uparrow C D \ldots$ corrected for fiber shrinkage: $305 \rightarrow 425$

Ingjer 1978, 1979 ... female ... $\uparrow$ CD: $1.39 \rightarrow 1.79(<0.005)$

Denis $1986 \ldots \uparrow C D:$ G20: $316 \rightarrow 396 \ldots$ G60: $308 \rightarrow 409$

Hather $1991 \ldots \uparrow C D$

Coggan $1992 \ldots \uparrow C D$... less so in aged males \& females

Hepple $1997 \ldots \uparrow C D$

Richardson $1999 \ldots \uparrow$ VEGF/18s: $0.38 \pm 0.04 \rightarrow 16.9 \pm 6.7 \ldots$ no effect with $\beta F G F$ mRNA

Gustafsson $1999 \ldots 3 \times$... $\uparrow$ VEGF \& VEGF mRNA ... FGF not increased

Gustafsson 2001, 2002 ... 2-3x $\uparrow$ VEGF \& VEGF mRNA

Ryan $2006 \ldots \uparrow$ VEGF/18s ... less so in aged

Gavin $2007 \ldots \uparrow C D, \uparrow$ VEGF ... lesser increase in aged

-- Animals ... 6 studies

Unger 1979 rats ... swimming $\rightarrow \uparrow$ myocardial capillary cell walls ... no signif. $\uparrow$ in aged rats

Adolfsson 1981 rats ... $\uparrow$ CD ... skeletal muscle ... less so in old rats

Breen 1996 rats ... $\uparrow$ VEGF, $\uparrow \mathrm{TGF}-\beta, \uparrow \beta \mathrm{FGF} \ldots$ skeletal muscle

Gavin 2000 rats ... $\uparrow$ receptor Flt for VEGF mRNA ... skeletal muscle

Amaral 2001 rats ... $\uparrow C D$... VEGF neutralizing Ab blocked angiogenesis ... skeletal muscle

Lloyd 2003 rats ... $\uparrow$ CD, $\uparrow$ VEGF ... skeletal muscle

5B. ELECTRICAL STIMULATION -- Animals only ... 10 studies in muscles

Brown 1976 rabbits ... $\uparrow \mathrm{CD}$

Hudlicka 1982 rabbits ... $\uparrow \mathrm{CD}$

Hang 1995 rats ... 6x $\uparrow$ VEGF mRNA

Annex 1998 rabbits ... 3x $\uparrow$ VEGF

Roca 1998 rats ... 3x $\uparrow$ VEGF mRNA ... no change in $\beta$ FGF or TGF- $\beta_{1}$

Skorjanc 1998 rabbits ... $\uparrow \mathrm{CD}, \uparrow$ VEGF mRNA

Kanno 1999 rats ... $\uparrow$ CD, $\uparrow$ VEGF ... ischemic hind limb

Milkiewicz 2001 rats ... $\uparrow$ VEGF

Verhaeg 2001 rats ... $\uparrow$ CD

Hudlicka 2002 rats/rabbits ... $\uparrow$ CD, $\uparrow$ VEGF 
Table 6. Ischemic Hind Limbs, Grafts, Wounds, \& Sponges Treated with Various AG Factors

6A. Ischemic hind limb model ... 5 studies ... $\uparrow=$ increase

-- Takeshita 1994, 1995 in rabbits ... VEGF, IV bolus $1 \mathrm{x} \rightarrow \uparrow C D$

-- Rivard 1999 in rabbits, mice ... VEGF, IV bolus 1x $\rightarrow \uparrow C D$

-- Baffour 1992 in rabbits ... rh bFGF, IM qd x2 wks $\rightarrow \uparrow C D$

-- Yang 1996 in rats ... bFGF, subQ pump x 14 days $\rightarrow \uparrow C D$

-- Witzenbichler 1998 in rabbits ... rh VEGF-C, IV bolus x1 $\rightarrow \uparrow$ CD

6B. Wounds (full thickness skin, sponge/gel implants, bone graft) ... 8 studies

-- Eppley 1988 in rabbits ... bone grafts ... bFGF $\rightarrow \uparrow$ vascularity \& healing

-- McGee 1988 in rats ... skin wound ... bFGF $\rightarrow$ “modest” $\uparrow$ healing

-- Beck 1990 in pigs ... skin wounds ... rhTGF- $\beta 1 \rightarrow \uparrow$ blood flow

-- Greenhalgh 1990 in mice ... skin wounds ... rbFGF \& rPDGF-BB $\rightarrow \uparrow C D$

-- Tsuboi 1990 in diabetic mice ... skin wounds ... $\beta$ FGF $\rightarrow \uparrow C D \&$ healing

-- Puolakkainen 1995 in aged rats ... skin wounds ... TGF- $\beta 1 \rightarrow \uparrow C D \&$ healing

-- Thompson 1988 in rats ... gelatin sponges in skin with aFGF $\rightarrow$ "significant angiogenesis"

-- Dellian 1996 in mice ... gel in skin chamber with VEGF \& $\beta$ FGF $\rightarrow \uparrow C D$

aFGF $=$ heparin binding growth factor

$\mathrm{PIGF}=\mathrm{rPDGF}-\mathrm{BB}=$ platelet derived growth factor

$\mathrm{qd}=$ every day

$\mathrm{rh}=$ recombinant human

VEGF = vascular endothelial growth factor 